\title{
THE ELECTROCARDIOGRAPHIC RECOGNITION OF VENTRICULAR HYPERTROPHY IN CONGENITAL CARDIO- VASCULAR DISEASE DURING THE FIRST YEAR OF LIFE
}

\author{
BY \\ J. S. OLDHAM \\ From the Children's Hospital and Dudley Road Hospital, Birmingham
}

(RECEIVED FOR PUBLICATION DECEMBER 9, 1957)

The value of electrocardiography in the elucidation of the diagnostic problems of congenital heart disease in infancy has been limited by lack of precise knowledge of normal features of the electrocardiogram in this age group. Battro and Mendy (1946) were the first to relate electrocardiographic patterns to age. Alimurung, Joseph, Nadas and Massell (1951) and Ziegler (1951) made detailed studies on large groups of infants and children, and their work provides standards of normality for all ages from birth to 14 years.

Publications about the electrocardiographic recognition of ventricular hypertrophy in infants are few. In these communications the existence of ventricular hypertrophy is inferred from the nature of the cardiac malformation, diagnosis being established by cardiac catheterization or contrast radiography. By these methods hypertrophy of the right ventricle may be reliably deduced, but as the techniques provide less information about the state of the left ventricle it may not be possible to distinguish between isolated right ventricular hypertrophy and combined ventricular hypertrophy.

It is the purpose of this paper to consider the value of the electrocardiogram in the determination of ventricular hypertrophy resulting from congenital cardiovascular disease in the first year of life, the type of ventricular hypertrophy and the nature of the malformation being proved by necropsy.

\section{Investigation}

Material. Forty infants were studied. Ages ranged from 2 days to 11 months at the time electrocardiograms were made. The majority of infants died within 6 months of birth. Tracings were obtained within two months of death in all cases except two, of these one child died at the age of 3 years, the other at 14 months. In 25 cases the cardiovascular lesion was one causing persistent cyanosis.
Method. In all cases standard limb leads, unipolar extremity leads and precordial leads $\mathrm{V} 1$, V2, V4 and V6 were used. A precordial electrode of small surface area (diameter $1.7 \mathrm{~cm}$.) was employed. The recording instrument was standardized before each tracing was made.

In the interpretation of tracings the following criteria were used. The $\mathbf{R}$ deflection was considered abnormal if in excess of the 99.5 percentile of observed or computed maximum for age (by the standards of Ziegler (1951)). The intrinsicoid deflection in V1 was considered to be delayed if occurring 0.04 second or longer after the beginning of the QRS complex in this lead (Goodwin, 1952).

Necropsy examinations were made in all cases. Ventricular hypertrophy was invariably present. In not all cases was the heart detached from other thoracic viscera for weighing, but when this was done, heart weights ranged from $150 \%$ to $340 \%$ of that normal for age (by the standards of Potter and Adair (1940)). Cases were grouped as isolated right ventricular hypertrophy, isolated left ventricular hypertrophy, or combined ventricular hypertrophy on the basis of necropsy findings. The major cardiovascular defect in each group was as follows:

ISOlated Right Ventricular HyPertrophy. (Total 20 cases.) Tetralogy of Fallot (6), single ventricle (3), complete transposition of the great vessels and pulmonary atresia (1), coarctation of aorta proximal to patent ductus arteriosus (2), mitral stenosis (1), isolated pulmonary stenosis (1), atrial septal defect (3), ventricular septal defect (1), congenital tricuspid incompetence (2).

ISOlATED LEFT VENTRICULAR HYPERTROPHY. (Total 3 cases.) Tricuspid atresia (2), tricuspid stenosis (1).

Combined Ventricular Hypertrophy. (Total 17 cases.) Complete transposition of the great vessels (6), persistent truncus arteriosus (1), coarctation of aorta proximal to patent ductus arteriosus 
TABLE 1

PATTERN OF QRS COMPLEX IN PRECORDIAL LEAD V1

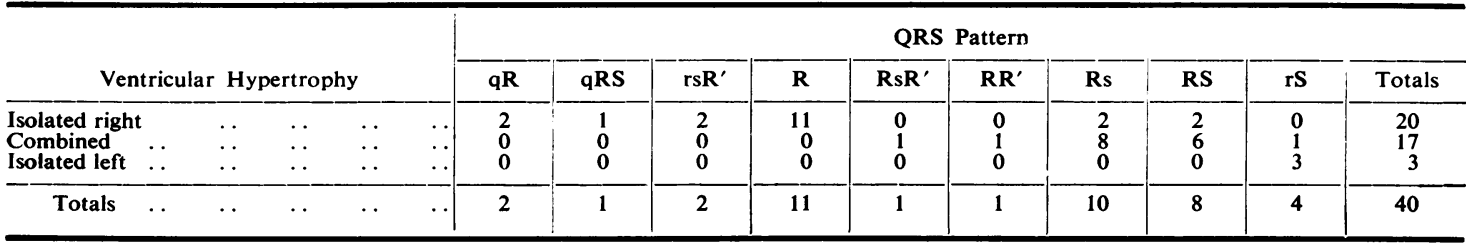

(1), endocardial fibro-elastosis (2), patent ductus arteriosus (2), persistent common atrio-ventricular canal (2), ventricular septal defect (3).

\section{Results}

Ventricular Complex in V1. The types of QRS complex observed are tabulated in Table 1 . In the two instances in which a $\mathrm{qR}$ pattern was present in $\mathrm{V} 1$, the complex in V2 was composed of a double peaked $R$ and the intrinsicoid deflection was delayed in this lead. The solitary example of a qRS deflection was provided by a heart with single ventricle. In this case an rss' pattern was present in $\mathrm{V} 2$.

Complexes of type $\mathbf{R}$, often slurred or notched on the upstroke, were observed only in cases of isolated right ventricular hypertrophy. In 14 of 17 cases of combined ventricular hypertrophy the ventricular complex was of form Rs or RS. An rS pattern was seen only with hypertrophy of the left ventricle, whether isolated or combined.

Cases of isolated right ventricular hypertrophy could be classified in three groups on the basis of the form of the QRS complex, the amplitude of $R$, and the polarity of the $T$ wave.

In the first group, of 11 cases, the intrinsicoid deflection was delayed. In 10 of these cases $T$ was negative. In seven $\mathrm{R}$ was of abnormally great amplitude. This group showed incomplete right bundle branch block patterns suggesting diastolic overloading of the right ventricle (Cabrera and Monroy, 1952).

In the second group, of six cases, the ventricular complex was formed of a solitary $\mathrm{R}$ deflection of normal amplitude and the intrinsicoid deflection was not delayed. $T$ was upright in four cases (abnormal in infancy except during the first 2 days of life), was isoelectric in one, and negative in one.

The third group of three cases showed features of extreme clockwise rotation of the heart, there being an initial $\mathrm{q}$ deflection. $\mathrm{T}$ was negative.

Of the 17 cases of combined ventricular hypertrophy, an incomplete right bundle branch block pattern with delay of the intrinsicoid deflection was present in 10 . In four of these $\mathrm{R}$ was of abnormally great amplitude. Of the remaining seven cases $R$ was abnormally tall in three.

Accepting as evidence of right ventricular hypertrophy either an amplitude of $R$ in excess of that normal for age, or delay of the intrinsicoid deflection, the condition could be detected in 11 of 17 cases $(65 \%)$ of isolated right ventricular hypertrophy (excluding from this analysis the three cases with $\mathrm{q}$ deflections), and in 13 of 17 cases $(75 \%)$ of combined ventricular hypertrophy.

Ventricular Complex in V6. $R$ was of amplitude in excess of that normal for age in one of three cases of isolated left ventricular hypertrophy, and in six of 17 cases of combined ventricular hypertrophy (Table 2). Delay of the intrinsicoid deflection was not of help in detecting left ventricular hypertrophy since in one case only did the intrinsicoid deflection occur after $0.04 \mathrm{sec}$, and in this case $R$ was of abnormally great amplitude.

TABLE 2

CORRELATION OF ELECTROCARDIOGRAPHIC EVIDENCE OF VENTRICULAR HYPERTROPHY, BASED ON ABNORMAL MEASUREMENTS OF VENTRICULAR COMPLEXES IN VI AND V6, WITH ANATOMICAL FINDINGS. (THE MEASUREMENTS WERE AMPLITUDE OF $R$ AND TIME OF ONSET OF INTRINSICOID DEFLECTION.)

\begin{tabular}{|c|c|c|c|c|c|}
\hline \multirow[b]{2}{*}{$\begin{array}{l}\text { Ventricular } \\
\text { Hypertrophy }\end{array}$} & \multicolumn{5}{|c|}{ E.C.G. Indication of Ventricular Hypertrophy } \\
\hline & $\begin{array}{l}\text { Right } \\
\text { Alone }\end{array}$ & $\begin{array}{c}\text { Right } \\
\text { and Left }\end{array}$ & $\begin{array}{l}\text { Left } \\
\text { Alone }\end{array}$ & $\begin{array}{c}\text { Normal } \\
\text { Measure- } \\
\text { ment }\end{array}$ & Totals \\
\hline $\begin{array}{l}\text { Isolated right } \\
\text { Combined } \\
\text { Isolated left } \ldots\end{array}$ & $\begin{array}{r}11 \\
8 \\
0\end{array}$ & $\begin{array}{l}0 \\
5 \\
0\end{array}$ & $\begin{array}{l}0 \\
1 \\
1\end{array}$ & $\begin{array}{l}6 \\
3 \\
2\end{array}$ & $\begin{array}{c}17^{*} \\
17 \\
3\end{array}$ \\
\hline Totals & 19 & 5 & 2 & 11 & $37^{*}$ \\
\hline
\end{tabular}

* 3 cases with qR or qRS patterns in VI excluded.

Ventricular Complex in VR. Extremity leads provide less direct evidence of ventricular hypertrophy than do precordial leads. VR was studied in the hope that it might provide information helpful in making distinction between isolated right ventricular hypertrophy and combined ventricular hypertrophy when the precordial elestro- 
TABLE 3

PATTERNS OF QRS COMPLEX IN VR

\begin{tabular}{|c|c|c|c|c|c|c|c|c|c|c|c|c|c|c|c|}
\hline \multirow{2}{*}{\multicolumn{6}{|c|}{ Ventricular Hypertrophy }} & \multicolumn{10}{|c|}{ QRS Pattern } \\
\hline & & & & & & QR & QRs & $\mathbf{q R}$ & qRs & $\mathbf{R}$ & $\mathbf{r s R}^{\prime}$ & $\mathbf{r S R}^{\prime}$ & rSrs & $\mathrm{rS}$ & Totals \\
\hline $\begin{array}{l}\text { Isolated right } \\
\text { Combined } \\
\text { Isolated left }\end{array}$ & $\ldots$ & $\begin{array}{l}\cdots \\
\cdots\end{array}$ & $\begin{array}{l}\ldots \\
\cdots\end{array}$ & $\begin{array}{l}\cdots \\
\cdots \\
\cdots\end{array}$ & $\begin{array}{c}\ldots \\
\cdots \\
\ldots\end{array}$ & $\begin{array}{l}4 \\
0 \\
0\end{array}$ & $\begin{array}{l}1 \\
0 \\
0\end{array}$ & $\begin{array}{l}3 \\
5 \\
0\end{array}$ & $\begin{array}{l}4 \\
0 \\
0\end{array}$ & $\begin{array}{l}2 \\
0 \\
0\end{array}$ & $\begin{array}{l}2 \\
4 \\
0\end{array}$ & $\begin{array}{l}2 \\
4 \\
0\end{array}$ & $\begin{array}{l}2 \\
2 \\
0\end{array}$ & $\begin{array}{l}0 \\
2 \\
3\end{array}$ & $\begin{array}{r}20 \\
17 \\
3\end{array}$ \\
\hline Totals & . & $\cdots$ & . & $\ldots$ & $\ldots$ & 4 & 1 & 8 & 4 & 2 & 6 & 6 & 4 & 5 & 40 \\
\hline
\end{tabular}

cardiogram indicated hypertrophy of the right ventricle alone.

Patterns of the ventricular complex are analysed in Table 3. Prominent $\mathbf{Q}$ deflections ( $Q$ more than one third the amplitude of $R$ ), or solitary $R$ deflections, occurred only in cases of isolated right ventricular hypertrophy. When complexes of these types were present in VR, there was usually an $R$ or $\mathrm{qR}$ pattern in V1. In two cases, however, a $\mathrm{QR}$ in VR was associated with an Rs complex in $\mathrm{V} 1$; in such cases VR may be helpful in distinguishing between isolated right and combined ventricular hypertrophy.

\section{Discussion}

Goodwin (1952) was the first to suggest criteria for the electrocardiographic recognition of right ventricular hypertrophy in young children. His subjects were aged from 3 to 14 years. His criteria were based on the time of onset of the intrinsicoid deflection, and on the patterns of the QRS complex in leads V1 and aVR.

Braunwald, Donoso, Sapin and Grishman (1955) found that 11 of 45 of their cases in a similar age group did not fulfil Goodwin's criteria. They studied 51 cases of presumed isolated right ventricular hypertrophy in children aged 1 to 15 years and found that $29(57 \%)$ exhibited an $R$ deflection in V1 of amplitude abnormal for age, and that in $26(51 \%)$ the pre-intrinsicoid deflection time in V1 was $0.04 \mathrm{sec}$. or longer. Accepting either of these criteria $41(80 \%)$ could be correctly diagnosed. The authors considered that these criteria were the most satisfactory then available.

Employing these criteria only $65 \%$ of my cases of isolated right ventricular hypertrophy would be recognized, though the presence of right ventricular hypertrophy could be detected in $75 \%$ of cases of combined ventricular hypertrophy (Table 2). Numbers are too small for this disparity in results to be of statistical significance. I believe, however, that these criteria may well be of less value in the recognition of isolated right ventricular hypertrophy during the first year of life than at later periods. Certain cases revealed complexes in V1 which, though normal by measurement, were of abnormal configuration, such as $\mathrm{qR}$, or $R$ with positive $T$; these abnormal patterns were not shown by cases of combined ventricular hypertrophy, and were associated with types of cardiovascular malformation which usually prove fatal within a few months of birth.

Ziegler (1956) described a pattern of ventricular complex in right precordial leads which he considered to be indicative of the most advanced degree of systolic overloading of the right ventricle. This pattern consists of an $\mathrm{R}$ deflection single or double peaked, of near $100 \%$ amplitude of RS, followed by an upright instead of inverted $\mathrm{T}$, and frequently preceded by a true initial $Q$ wave. This type of complex was observed in five of my cases; in four of these $R$ was of normal amplitude and the intrinsicoid deflection was not delayed; the existence of right ventricular hypertrophy thus could not be detected by measurement.

Ventricular complexes in $\mathrm{V} 1$ of the form $\mathrm{qR}$ (with negative $T$ ) were considered to be always abnormal by Goodwin (1952) and by Goldberger (1953). Goodwin (1952) and Brink and Neill (1955) regarded this pattern in V1 as indicative of right ventricular hypertrophy. No example was present in the large series of normal infants and children studied by Alimurung et al. (1951) but Ziegler (1951) found three examples in normal infants under 3 months of age.

The two cases showing a $\mathrm{qR}$ pattern in V1 in my series revealed other abnormalities in the electrocardiogram, in particular the ventricular complex in V2 was composed of a double peaked $R$ wave, the intrinsicoid deflection being delayed, a pattern which when occurring in V1 is characteristic of right ventricular hypertrophy in this age group.

Only in a minority of cases of combined ventricular hypertrophy does direct measurement of the ventricular complexes in left precordial leads provide unequivocal evidence of hypertrophy of the left ventricle. In about $50 \%$ of cases the electrocardiogram permits the recognition of right ventricular hypertrophy alone (Table 2).

Ziegler (1956) suggested that, with QRS or T 
wave evidence of right ventricular hypertrophy in right precordial leads, the occurrence of $T$ wave inversion in leads from the left side of the precordium was strong presumptive evidence of associated left ventricular hypertrophy. In my series such $\mathrm{T}$ wave inversion occurred only in cases in which the $\mathrm{R}$ deflection in V6 was of abnormally great amplitude, itself an indication of left ventricular hypertrophy.

More helpful was the configuration of the ventricular complex in V1, since patterns of the forms $\mathrm{R}$ or $\mathrm{qR}$ were encountered only in cases of isolated right ventricular hypertrophy. The form of the complex in VR may also be of some value in making distinction between isolated right and combined ventricular hypertrophy because in the latter condition $\mathrm{QR}$ and $\mathrm{R}$ patterns were not observed.

\section{Conclusions}

It is emphasized that the material forming the basis of this study is not fully representative of congenital cardiovascular disease in infancy. The methods employed in selection were such that the series is necessarily composed of the more severe types of malformation. With this qualification the following conclusions are drawn regarding electrocardiographic findings during the first 12 months of life.

In about $90 \%$ of cases of isolated right ventricular hypertrophy the ventricular complexes in $\mathrm{V} 1$ are abnormal. Abnormalities are of three types: (a) The intrinsicoid deflection is delayed to $0.04 \mathrm{sec}$. or longer and/or $\mathrm{R}$ is of amplitude in excess of that normal for age. (b) The ventricular complex is in the form of a solitary $R$ deflection which is followed by an upright $\mathrm{T}$ wave. (c) There is an initial $\mathrm{q}$ deflection.

Combined ventricular hypertrophy can be recognized in about $30 \%$ of cases from the presence in $\mathrm{V} 1$ of an $\mathrm{R}$ deflection of amplitude in excess of that normal for age and/or prolongation of the pre- intrinsicoid deflection time to $0.04 \mathrm{sec}$. or longer, together with a $\mathrm{qR}$ or qRs pattern in V6 in which $\mathrm{R}$ is of amplitude in excess of that normal for age. In about $50 \%$ of cases of combined ventricular hypertrophy the electrocardiogram reveals hypertrophy of the right ventricle alone.

When the electrocardiogram is indicative of right ventricular hypertrophy alone this is likely to be isolated if the ventricular complex in V1 is of the form $\mathrm{qR}$ or $\mathrm{R}$, or the ventricular complex in VR is of the form $\mathrm{QR}$ or $\mathrm{R}$.

\section{Summary}

Electrocardiograms were obtained during the first year of life from 40 infants with congenital cardiovascular disease.

The presence of isolated right ventricular hypertrophy, combined ventricular hypertrophy, or isolated left ventricular hypertrophy, was later proved by necropsy.

The value of electrocardiography in the recognition of ventricular hypertrophy, and in making distinction between isolated right ventricular hypertrophy and combined ventricular hypertrophy, is discussed.

I am grateful to physicians on the staff of the Birmingham Children's Hospital for permission to study cases admitted under their care. I am particularly indebted to Dr. C. G. Parsons for encouragement and valuable criticism, to Dr. H. S. Baar for necropsy reports, and to Miss Jean Wright who obtained most of the electrocardiograms.

\section{REFERENCES}

Alimurung, M. M. Joseph, L. G., Nadas, A. S and Massell, B. F (1951). Circulation, 4, 420.

Battro, A. and Mendy, J. C. (1946). Arch. intern. Med., 78, 31.

Braunwald, E., Donoso, E., Sapin, S. O. and Grishman, A. (1955). Amer. Heart J., 50, 591 .

Brink, A. J. and Neili, C. A. (1955). Circulation, 12, 604.

Cabrera, E. and Monroy, J. R. (1952). Amer. Heart J., 43, 661, 669.

Goldberger, E. (1953). Unipolar Lead Electrocardiography and Vectorcardiography, 3rd ed. London.

Goodwin, J. F. (1952). Brit. Heart J., 14, 173. Potter, E. L. and Adair, F. L. (1940). Fetal and Neonatal Death.

Ziegler, R. F. (1951). Electrocardiographic Studies in Normal Infants and Children. Springfield, Illinois.

(1956). Amer. Heart J., 52, 533. 